\title{
REPORT OF FINDINGS
}

\section{CLINICAL TRIALS OF BORON NEUTRON CAPTURE THERAPY \\ AT \\ BETH ISRAEL DEACONESS MEDICAL CENTER}

Submitted to the U.S. Department of Energy

Office of Biological \& Environmental Research

May 29, 2001

By

HYGEIA Research Associates, Inc.

6268 Jericho Turnpike, Suite 2

Commack, New York 11725

Tel: (631) 858-1800 Fax: (631) 858-1802

e-mail: cwallace@hygeia-research.com

\section{Principal Investigator}

Christine Wallace RN, MS Vice President

DOE Patent Clearance Granted

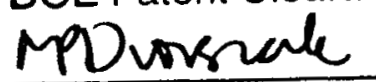

Mark P. Dvorscak

$\frac{7 / 24 / 01}{0 \text { ate }}$ (630) 252-2393

E-mail: mark.dvorscak@ch.doe.gov

Office of intellectual Property Law

DOE Chicago Operations Office 


\section{DISCLAIMER}

This report was prepared as an account of work sponsored by an agency of the United States Government. Neither the United States Government nor any agency Thereof, nor any of their employees, makes any warranty, express or implied, or assumes any legal liability or responsibility for the accuracy, completeness, or usefulness of any information, apparatus, product, or process disclosed, or represents that its use would not infringe privately owned rights. Reference herein to any specific commercial product, process, or service by trade name, trademark, manufacturer, or otherwise does not necessarily constitute or imply its endorsement, recommendation, or favoring by the United States Government or any agency thereof. The views and opinions of authors expressed herein do not necessarily state or reflect those of the United States Government or any agency thereof. 


\section{DISCLAIMER}

Portions of this document may be illegible in electronic image products. Images are produced from the best available original document. 


\section{SUMMARY}

The Food and Drug Administration (FDA) has designated the Boron Neutron Capture Therapy (BNCT) project a significant risk (SR) device study based on the potential for serious risk to the health, safety, or welfare of the subjects. Hence, the FDA requires more stringent guidelines with regard to the approval process, record keeping and reporting requirements for the study when compared to a nonsignificant risk (NSR) study. Both the sponsor and the investigators must comply with the Investigational Device Exemptions (IDE) regulations [21 CFR part 812], informed consent and IRB regulations [21 CFR Parts 50 and 56], and the FDA's publication entitled ICH Guideline for Good Clinical Practice. The intent of the latter guideline is to provide "a unified standard for designing, conducting, recording, and reporting trials that involve the participation of human subjects". Additionally, the guideline details the essential documents required that permit evaluation of the conduct of clinical trials and the quality of the data captured.

The scope of this project, funded by the Department of Energy, was to review the research records at the two sites conducting BNCT studies, Brookhaven National Laboratory and at Beth Israel Deaconess Medical Center utilizing the aforementioned criteria. The project began in May 1999, and the review process was completed in August 1999. Preliminary results of the review were presented on July 12,1999 at the BERAC subcommittee meeting held in Cambridge, Massachusetts. A summary of sitespecific deficiencies is identified below, and documentation may be found in the body of the report.

\section{Beth Israel Deaconess Medical Center}

The research and IRB records were maintained in a secured area. The organization of the records was in compliance with federal regulatory standards. The major deficiencies at the site include the:

- Failure to report all Serious Adverse Events (major violation),

- Poor follow-up data; (only $41 \%$ of the research charts had evidence of follow-up categorized as $70-100 \%$ complete (major violation),

- Practice of obtaining study required testing prior to obtaining informed consent (major violation),

- Absence of toxicity scoring as written in their research protocol (major violation),

- Enrollment of four subjects who possibly did not meet entry criteria (possible major violation),

- Absence of some source documentation to support eligibility (minor violation),

It is the responsibility of the principal investigators to ensure the accuracy, completeness, legibility and timeliness of the data as well ensure that all staff assisting with the trial are adequately informed about the protocol, study treatment, and their trialrelated duties and functions (Guideline for Good Clinical Practice 4.2.4). Physicians following the subjects from other facilities should receive clear instructions regarding the required follow-up procedures and instructions regarding Good Clinical Practice and other FDA guidelines. With regard to this project, some physicians were consistently conscientious with follow-up, reporting all required data in an accurate manner, while others provided incomplete or inaccurate data on a consistent basis. 


\title{
REPORT OF FINDINGS
}

\section{CLINICAL TRIALS OF BORON NEUTRON CAPTURE THERAPY AT BROOKHAVEN NATIONAL LABORATORY}

\author{
Submitted to the U.S. Department of Energy \\ Office of Biological \& Environmental Research \\ May 29, 2001 \\ By \\ HYGEIA Research Associates, Inc. \\ 6268 Jericho Turnpike, Suite 2 \\ Commack, New York 11725 \\ Tel: (631) 858-1800 Fax: (631) 858-1802 \\ e-mail: cwallace@hygeia-research.com
}

Principal Investigator

Christine Wallace RN, MS

Vice President 


\section{SUMMARY}

The Food and Drug Administration (FDA) has designated the Boron Neutron Capture Therapy (BNCT) project a significant risk (SR) device study based on the potential for serious risk to the health, safety, or welfare of the subjects. Hence, the FDA requires more stringent guidelines with regard to the approval process, record keeping and reporting requirements for the study when compared to a nonsignificant risk (NSR) study. Both the sponsor and the investigators must comply with the Investigational Device Exemptions (IDE) regulations [21 CFR part 812], informed consent and IRB regulations [21 CFR Parts 50 and 56], and the FDA's publication entitled ICH Guideline for Good Clinical Practice. The intent of the latter guideline is to provide "a unified standard for designing, conducting, recording, and reporting trials that involve the participation of human subjects". Additionally, the guideline details the essential documents required that permit evaluation of the conduct of clinical trials and the quality of the data captured.

The scope of this project, funded by the Department of Energy, was to review the research records at the two sites conducting BNCT studies, Brookhaven National Laboratory and at Beth Israel Deaconess Medical Center utilizing the aforementioned criteria. The project began in May 1999, and the review process was completed in August 1999. Preliminary results of the review were presented on July 12, 1999 at the BERAC subcommittee meeting held in Cambridge, Massachusetts. A summary of sitespecific deficiencies is identified below, and documentation may be found in the body of the report.

\section{Brookhaven National Laboratory}

The research and IRB records were maintained in a secured area. The organization of records was not in compliance with federal regulatory standards. Deficiencies at the site included:

- Informed consent not obtained from one subject prior to treatment and not obtained from 24 subjects prior to initiating pretreatment study procedures (major violation);

- Failure to report all Serious Adverse Events and unanticipated events (major violation);

- Retrospective changing of subjects' entry criteria (KPS scores) without evidence of new data (major violation);

- Use of presigned and predated Standing Order Forms for 18 subjects (major violation); the worst offense was a Standing Order signed and dated 13 months prior to its use;

- Use of source documents as the Case Report Forms; (major violation);

- Evidence of protocol violations due to the enrollment of 8 subjects who did not meet the study" entry criteria of a Karnofsky Performance Score equal to or greater than 70 , based on the objective documentation found on the pretreatment not (major violation);

- Numerous questions (45) regarding subjects' eligibility for study entry: (missing reports, missing depth of tumor documentation in reports, missing notes with objective findings to support KPS scores, anti-seizure medication serum levels below therapeutic range, presence of second foci on brain scan at pretreatment, presence of metal implants in subjects' heads, and incomplete tumor debulking for one subject on Protocol 6) (major violation); 
- Failure to ensure complete and accurate data submission from participating institutions; e.g., disparity between KPS scores and clinical findings, blanks left on forms for objective findings or results, disparity between subject's clinical status and the reporting of disease response, and use of white-out to obscure data and

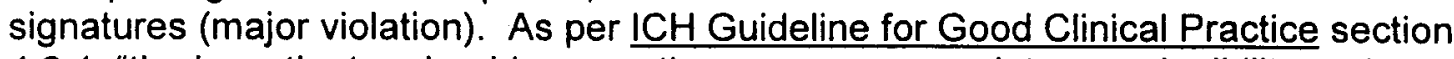
4.9.1, "the investigator should ensure the accuracy, completeness, legibility and timeliness of the data reported to the sponsor in the $C$ (ase) R(eport) $F$ (orm)s and in all required reports."

- Radiographic data were not presented in a standardized and evaluable manner for determination of eligibility, side effects, response to treatment, or progression of disease. These source documents were not comparable.

It is the responsibility of the principal investigators to ensure the accuracy, completeness, legibility and timeliness of the data as well ensure that all staff assisting with the trial are adequately informed about the protocol, study treatment, and their trialrelated duties and functions (Guideline for Good Clinical Practice 4.2.4). Physicians following the subjects from other facilities should receive clear instructions regarding the required follow-up procedures and instructions regarding Good Clinical Practice and other FDA guidelines. With regard to this project, some physicians were consistently conscientious with follow-up, reporting all required data in an accurate manner, while others provided incomplete or inaccurate data on a consistent basis.

These deficiencies represent a significant deviation from the standards for conducting, recording, and reporting of clinical trials as outlined by the FDA. 